\title{
Surgical Needs at the End of the Battle of Mosul: Results from Mosul General Hospital
}

\author{
Fredrik Bäckström ${ }^{1,2} \cdot$ Denise Bäckström ${ }^{1} \cdot$ Lin Sadi $^{3} \cdot$ Peter Andersson $^{1,4,5}$. \\ Andreas Wladis ${ }^{1,2,3}$
}

Published online: 1 November 2019

(C) The Author(s) 2019

\begin{abstract}
Purpose The aim of the study was to analyze the surgical needs of patients seeking emergency care at the Mosul General Hospital in the final phase of the battle of Mosul in northern Iraq between an international military coalition and rebel forces. During the conflict, the International Red Committee of the Red Cross (ICRC) supported the hospital with staff and resources. Ceasefire in the conflict was declared at the end of July 2017.

Methods Routinely collected hospital data from the ICRC-supported Mosul General Hospital from June 6, 2017, to October 1, 2017 were collected and analyzed retrospectively. All patients with weapon-related injuries as well as all patients with other types of injuries or acute surgical illness were included.

Results Some 265 patients were admitted during the study period. Non-weapon-related conditions were more common than weapon-related (55.1\%). The most common non-weapon-related condition was appendicitis followed by hernia and soft tissue wounds. Blast/fragment was the most frequent weapon-related injury mechanism followed by gunshot. The most commonly injured body regions were chest and abdomen. Children accounted for $35.3 \%$ of all weapon-related injuries. Patients presented at the hospital with weapon-related injuries more than 2 months after the official declaration of ceasefire. A majority of the non-weapon-related, as well as the weapon-related conditions, needed surgery $(88.1 \%$ and $87.6 \%$, respectively). Few postoperative complications were reported.

Conclusions The number of children affected by the fighting seems to be higher in this cohort compared to previous reports. Even several months after the fighting officially ceased, patients with weapon-related injuries were presenting. Everyday illnesses or non-weapon-related injuries dominated. This finding underlines the importance of providing victims of conflicts with surgery for life-threatening conditions, whether weapon related or not.
\end{abstract}

Fredrik Bäckström

fbm.nrk@gmail.com

1 Department of Clinical and Experimental Medicine, Linköping University, Linköping, Sweden

2 Centre for Teaching and Research in Disaster Medicine and Traumatology, University Hospital, Linköping, Sweden

3 Department of Surgery, Capio St. Göran's Hospital, Stockholm, Sweden
4 Department of Surgery, Vrinnevi Hospital, 60379 Norrköping, Sweden

5 International Medical Program, Centre for Teaching and Research in Disaster Medicine and Traumatology, University Hospital, Linköping, Sweden 


\section{Introduction}

Civilians are often severely affected by armed conflict and have constituted $30-51 \%$ of the victims in recent conflicts [1]. Reports from Syria suggest that civilian deaths constitute over $70 \%$ of the total deaths. Civilians are often injured by explosive weapons such as mortars, grenades, missiles, bombs, and mines which have been widely used in Syria since 2011 [1-3]. These types of weapons are hard to direct at specific military objectives and the effects are difficult to limit. They are often referred to as indiscriminate weapons. When used in densely populated areas and/ or in close proximity to civilians, the effects are often severe. While combatants are protected from such weapons with armored vehicles, fortifications, and personal protection equipment, civilians are not. The widespread use of these devices has successively increased civilian deaths and injuries in this conflict [2, 4]. In 2011, deaths of children constituted approximately $9 \%$ of war-related deaths in Syria. In 2016, this had increased to over 23\% [2].

The Battle of Mosul, Iraq's second-largest city, officially raged from October 16, 2016, to July 9, 2017. Over these 9 months, more than 940,000 civilians fled the city [5]. At least 30,000 government-led forces, backed by an international coalition, fought to retake the city from the insurgent fighters. The fighting was intense and has been described as the largest urban siege since World War II. Civilians trapped within the city between the opposed fighting forces faced sniper fire from the insurgents, mortar and artillery shelling from both sides, and coalition airstrikes $[6,7]$.

When the battle began, the World Health Organization (WHO) coordinated a complex operation where trauma pathways, modeled after military trauma systems involving several levels of care, were organized. This included trauma stabilization points (TSPs) located close to the actual fighting, ideally within $10 \mathrm{~min}$ from the frontline, ambulance services, and medical facilities (field hospitals), ideally within an hour's drive. These TSPs, ambulance services, and medical facilities were operated and staffed by both non-governmental organizations (NGOs) and private, for-profit medical companies. The TSPs were operated by NYC Medics and the different field hospitals by Aspen Medical, Samaritan's Purse, Médecins Sans Frontières (MSF), and the International Committee of the Red Cross (ICRC) [7].

Indiscriminate weapons such as landmines, unexploded ordnance (UXO), and improvised explosive devices (IED) often continue to claim lives and cause injury long after an armed conflict has officially ended. In order to understand medical needs at the end of an intense battle in a densely populated area such as Mosul, we analyzed routinely collected hospital data from ICRC-supported Mosul General Hospital from June 6, 2017, to October 1, 2017. The ICRC is a neutral and independent humanitarian organization based in Geneva, Switzerland that impartially provides assistance to victims of war and other situations of violence by deploying specialized staff and other resources in conflict zones around the world.

The aim of this study was to define patterns of injury and surgical conditions affecting the population of Mosul. We also wanted to study the type of treatment given to sick and injured patients admitted to the ICRC-supported hospital in Mosul during the final stages as well as after the official end of the battle of Mosul from June 2017 to October 2017.

\section{Patients and methods}

All surgical patients admitted to the ICRC-supported Mosul General Hospital from June 6, 2017, to October 1, 2017, were included. Patients with weapon-related injuries as well as patients with other types of acute surgical illness were admitted. Patients with obstetric and obvious major orthopedic conditions and no other life-threatening injuries and need for acute surgery were referred to other medical facilities and were therefore not included.

Information was retrospectively obtained from patient files regarding sex, age, time since injury, mechanism of injury, and body region affected. Treatment given whether weapon-related condition or not, as well as outcome defined as in-hospital death or discharge, were noted. Diagnosis at discharge was also noted. Whether patients were combatants or civilians could not be determined from the patient files. In keeping with previous reports from ICRC patient cohorts, patients younger than 16 years of age were classified as children and patients 16 years and older as adults [8].

\section{Statistical methods}

Statistical analysis was done using IBM SPSS Statistics software version 24 (IBM Corporation, Armonk, NY, USA). Values are given as median (IQR) when applicable. Comparison between groups was done by cross-table analysis (Chi 2) or nonparametric tests (Mann-Whitney U) when appropriate. The significance level was set to $p<0.05$ two-tailed test.

\section{Results}

The total number of patients admitted according to the admission criteria at the Mosul General Hospital during the study period was 265 and, of these, 88 (33.2\%) were 
female. Non-weapon-related conditions were more common than weapon-related, $n=146$ (55.1\%) (Fig. 1). Gender distribution, age, length of hospital stay, and percentage receiving surgery in each group are given in Table 1. Only one patient in this cohort died $(0.03 \%)$. There was a declining trend of weapon-related injuries and an increase in non-weapon-related injuries during the study period (Fig. 2).

\section{Adults}

The majority of the patients in this study were adults $n=169(64.2 \%)$, of whom, $55(32.5 \%)$ were female.

\section{Weapon-related injuries in adults}

The number of adults injured by weapons was 77 (45.6\%); the most common mechanism of injury was blast/fragment ( $n=46,59.7 \%)$, gunshot wound (GSW) $(n=25,32.5 \%)$, other $(n=4,5.2 \%)$, and burns $(n=2,2.6 \%)$. Adults accounted for $64.7 \%$ of all weapon-related conditions in the cohort. Adults with weapon-related injuries were more likely to have surgery and were hospitalized longer than those with non-weapon-related conditions (Table 2).

The most commonly injured body regions in the injuredby-weapons patients were chest and abdomen $(n=48$, $62.3 \%)$ followed by legs $(n=32,41.6 \%)$, arms $(n=23$, $29.9 \%)$, and head $(n=12,15.6 \%)$. More than third of the injured had two or more body regions injured $(n=32$, $41.6 \%$ ). There was no difference in injured body regions related to age (Fig. 3).

Time since injury was documented for $33(42.9 \%)$ of the adults injured by weapons, median $2.0(\mathrm{IQR}=1.0-8.0)$ hours. Time since injury did not differ between the sexes. The vast majority ( $n=66,85.7 \%$ ) of adult patients with weapon-related injuries needed surgery. There was no difference between sexes for all procedures or for specific procedures such as thoracotomy, chest tube insertion, laparotomy, or amputation. Most of the weapon-injured patients $(n=4558.4 \%)$ needed surgery only once, 11 $(14.3 \%)$ needed surgery twice, two $(2.6 \%)$ needed surgery three times, and seven $(9.1 \%)$ needed surgery four times or more.

No short-term postoperative complications were reported.

\section{Non-weapon-related conditions in adults}

A majority of the adults had non-weapon-related conditions $(n=94,55.0 \%)$. The most common non-weapon- related condition was appendicitis ( $n=26$ 27.7\%) followed by hernia $(n=16,17.0 \%)$ and abscesses $(n=9$, $9.6 \%$ ). Most of the patients with non-weapon-related conditions, 84 (89.4\%), needed surgery. Multiple surgeries were only needed for one patient $(1.1 \%)$ in this group, a person injured after a road traffic accident (RTA). This patient needed three surgeries. None of the victims of RTAs was over 20 years of age, and three were under 12 years of age (see below). All these patients needed surgery.

No short-term postoperative complications were reported.

\section{Children (0-15 years)}

The number of children in this study was 94 (35.5\%), 35 $(37.2 \%)$ of whom were girls. Children above the age of 10 $(n=25)$ were predominantly boys $(n=20,80 \%)$. Information on whether the injury was weapon-related injury or not and on gender distribution, age, length of hospital stay, and the percentage receiving surgery is given in Table 3.

\section{Weapon-related injuries in children}

The number of children injured by weapons was 42 (44.7\%); the most common mechanism of injury was blast/ fragment $(n=27,64.3 \%)$, followed by GSW $(n=8$, $19.0 \%)$, other $(n=4,9.5 \%)$, and burns $(n=3,7.1 \%)$. Children accounted for $35.3 \%$ of all weapon-related conditions in the cohort.

Children with weapon-related injuries were more likely to have surgery and were hospitalized longer than those with non-weapon-related conditions (Table 3). Injured body regions in children were chest and abdomen $(n=28$, $66.7 \%)$, arms $(n=13,31.0 \%)$, head $(n=13,31.0 \%)$, and legs $(n=12,28.6 \%$ ) (Fig. 3). More than third of the children had two or more body regions injured $(n=15$, $35.7 \%$.)

Time since injury was documented for $18(42.9 \%)$ children injured by weapons, median $1.0(\mathrm{IQR}=0.5-14.3)$ hours; there was no difference between boys and girls. There was no difference between sexes for all procedures or for specific procedures such as thoracotomy, chest tube insertion, laparotomy, or amputation. Most of the weaponinjured patients, $(n=2661.9 \%)$, needed surgery only once, $4(9.5 \%)$ needed surgery twice, three $(7.1 \%)$ needed surgery three times, and five (11.9\%) needed surgery four times or more.

There was one postoperative wound infection after a trauma laparotomy needing wound revision, but no other postoperative short-term complications were reported. 
Fig. 1 Distribution of diagnoses in patients treated at the Mosul General Hospital. GSW $=$ Gunshot wound, RTA $=$ Road traffic accident, PNS $=$ Pilonidal sinus, Fragment $=$ Shrapnel and fragment wounds

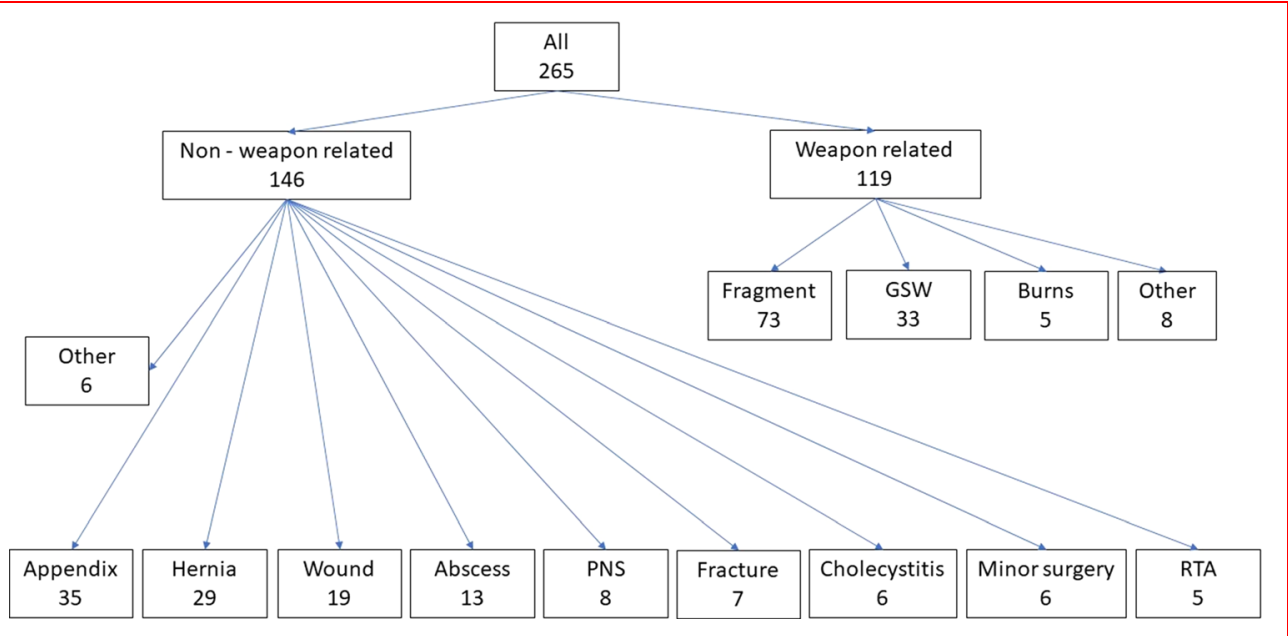

Table 1 Non-weapon-related injuries and weapon-related injuries

\begin{tabular}{|c|c|c|c|c|}
\hline & All $n=265$ & Non-weapon related $n=146$ & Weapon related $n=119$ & $p$ value \\
\hline Gender men/women & $177 / 88$ & $95 / 51$ & $82 / 37$ & 0.509 \\
\hline Age, years (IQR) & $22.0(10.0-35.0)$ & $22.0(10.0-35.8)$ & $22.0(10.0-33.0)$ & 0.986 \\
\hline Length of stay, days (IQR) & $1.0(0.0-5.0)$ & $0.0(0.0-1.0)$ & $5.0(1.0-8.0)$ & $<0.001$ \\
\hline Number of patients receiving surgery/not surgery & $227 / 33^{\mathrm{a}}$ & $123 / 19^{\mathrm{b}}$ & $104 / 14^{\mathrm{c}}$ & 0.715 \\
\hline
\end{tabular}

Median and IQR, Mann-Whitney U, and Chi 2 as appropriate for comparison between groups

${ }^{\mathrm{a}}$ Missing $5,{ }^{\mathrm{b}}=$ Missing $4,{ }^{\mathrm{c}}=$ Missing 1

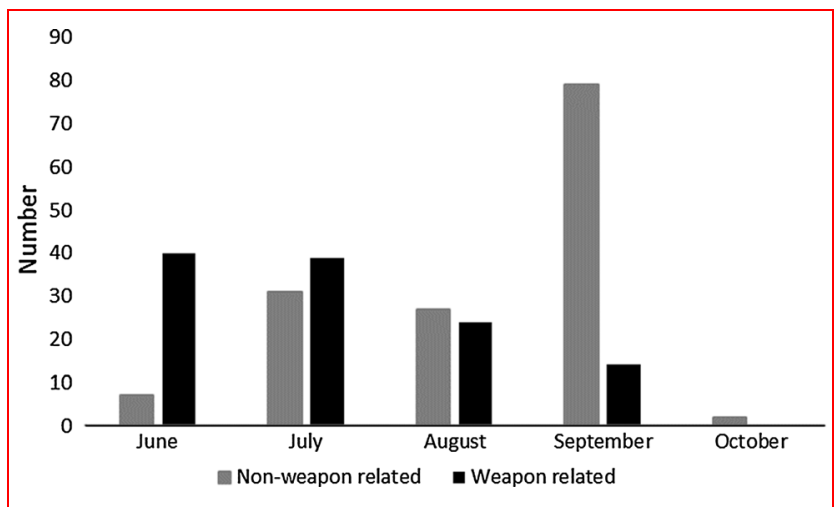

Fig. 2 Distribution of weapon injuries and non-weapon injuries during the study period

\section{Non-weapon-related conditions}

A majority of the children $(n=52,55.3 \%)$ had nonweapon-related conditions. Non-weapon-related conditions were hernia ( $n=13,25.0 \%$ ), soft tissue wound ( $n=12$, $23.1 \%)$, appendicitis $(n=9,17.3 \%)$, fractures $(n=5$, $9.6 \%)$, abscess $(n=4,7.7 \%)$, RTA $(n=3,5.8 \%)$, and blunt trauma $(n=3,5.8 \%)$. All the three children injured by RTA were under 12 years of age. All these patients needed surgery.

Most of the patients with non-weapon-related conditions, 41 (78.8\%), needed surgery. Multiple surgeries were only needed for one patient $(1.9 \%)$ in this group, injured after an RTA. This patient needed three surgeries. Children accounted for $35.6 \%$ of all non-weapon-related conditions.

No short-term postoperative complications were reported.

\section{Differences between children and adults}

The gender distribution in the cohort did not differ between children and adults. A longer length of stay was seen in weapon-related injuries in both children and adults, but there was no general difference between children and adults in the length of stay. There was no difference in injured body regions between children and adults except for head injuries which were more common in children than in adults ( $p=0.049)$ (Fig. 3). There was no difference in the procedures that were performed (Fig. 4). 
Table 2 Non-weapon-related injuries and weapon-related injuries in adults ( $>15$ years)

\begin{tabular}{|c|c|c|c|c|}
\hline & All $n=169$ & Non-weapon related $n=94$ & Weapon related $n=77$ & $p$ value \\
\hline Gender men/women & $116 / 55$ & $59 / 35$ & $57 / 20$ & 0.117 \\
\hline Age, years (IQR) & $30.0(22.0-45.0)$ & $30.0(22.8-47.0)$ & $29.0(22.0-40.0)$ & 0.643 \\
\hline Length of stay, days (IQR) & $1.0(0.0-4.0)$ & $0.0(0.0-1.0)$ & $3.0(1.0-8.0)$ & $<0.001$ \\
\hline Number of patients receiving surgery/not surgery & $149 / 18^{\mathrm{a}}$ & $83 / 8^{\mathrm{b}}$ & $66 / 10^{\mathrm{c}}$ & 0.365 \\
\hline
\end{tabular}

${ }^{\mathrm{a}}$ Missing $4,{ }^{\mathrm{b}}$ Missing $3,{ }^{\mathrm{c}}$ Missing 1

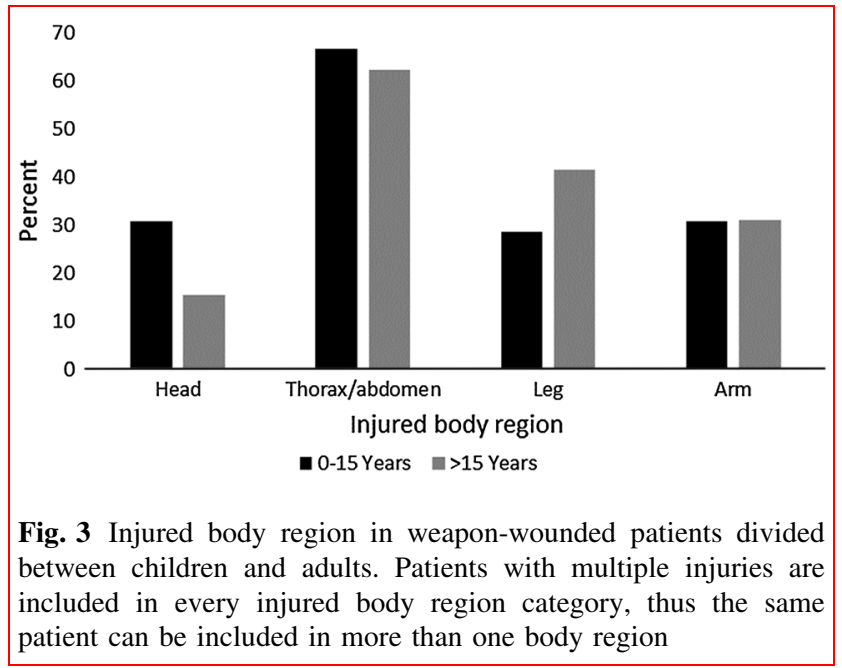

\section{Discussion}

Two of the salient findings in this study are the high number of children in the cohort as well as the large number of children injured by weapons used in the fighting in and around Mosul compared to previous reports $[2,9-11]$ where children account for approximately $5-18 \%$ of the patient workload. The reason for this might be a large number of civilians and children trapped within the city of Mosul between the opposed fighting forces as the battle raged on and there was no safe escape route. It was also surprising to find that the weapon-related injuries continued to present at the hospital more than 2 months after the military operations were declared over and Mosul was officially liberated. This may be due to mines, IEDs, UXOs, and booby traps left behind in houses and homes in and around Mosul.

As per ICRC principles of impartiality, all patients meeting standard admission criteria were treated at Mosul General Hospital without any distinction between combatants or civilians. A large proportion of the weapon wounded was injured in the trunk (thorax/abdomen) and had multiple fragment wounds suggesting that most of the patients were either civilians or combatants who did not use body armor commonly worn by soldiers in regular armed forces [12]. Recent reports state that in the Syrian conflict more than half of the mortally wounded civilians were killed by so-called "wide-area weapons," i.e., indiscriminate weapons. In contrast, only $9.6 \%$ of the combatants were killed by this kind of weapons [2].

Another reason for the relatively high proportion of patients with injuries to the chest and/or abdomen is the fact that patients with orthopedic limb injuries were transferred to a nearby hospital in Hamam al Aleel according to an agreement with the Qatari Red Crescent Society who managed this hospital at the time. Hence, such patients were never admitted to Mosul General Hospital and consequently not included in the study.

In our small cohort of weapon-wounded children, there was a preponderance of boys over girls. Reports from Syria indicate that boys seem to be at a greater risk of getting injured and killed and seem to have a higher risk of getting killed by firearms than girls [2,13]. Older boys are especially at higher risk $[2,13,14]$. This might be due to their

Table 3 Non-weapon-related injuries and weapon-related injuries in children ( $0-15$ years)

\begin{tabular}{|c|c|c|c|c|}
\hline & All $n=94$ & Non-weapon related $n=52$ & Weapon related $n=42$ & $p$ value \\
\hline Gender boys/girls & $61 / 33$ & $36 / 16$ & $25 / 17$ & 0.327 \\
\hline Age, years (IQR) & $8.5(4.9-12.0)$ & $8.0(2.3-12.0)$ & $9.0(6.5-10.5)$ & 0.315 \\
\hline Length of stay, days (IQR) & $1.0(0.0-6.0)$ & $0.0(0.0-1.0)$ & $6.0(2.5-9.5)$ & $<0.001$ \\
\hline Number of patients receiving surgery/not surgery & $78 / 15^{\mathrm{a}}$ & $40 / 11^{\mathrm{a}}$ & $38 / 4$ & 0.116 \\
\hline
\end{tabular}

Median and IQR, Mann-Whitney U, and Chi 2 as appropriate for comparison between groups

${ }^{\mathrm{a}}$ Missing 1 
spending more time outdoors than younger children or that they, the older they get, might be mistaken for a combatant and targeted as one [15]. They also have a higher risk of getting injured due to a greater interest in manipulating old mines and explosives [14, 16]. It has previously been shown that civilians are often wounded by mines and explosives left from earlier conflicts [16]. From the Syrian conflict, the most common injury mechanism in children seems to be injuries caused by bombs or missiles and bullets [13] and our results have a similar pattern. However, in our study, we could not find any difference in the types of injuries among children depending on gender. We found few differences in the injuries in children compared to adults, which could be due to the low number of weapon-wounded patients in our study; we found, however, more head injuries which have also been reported previously, and the reason for this is unclear [9, 17].

Although we only have limited information about time from injury to arrival to the hospital, we found that the time interval was shorter than in other reports from ICRC hospitals in other conflict areas [8]. The reason for the shorter prehospital times in our study could be that the distance between front line and/or point of injury and the hospital along the referral pathway that was set up by WHO was shorter than in other contexts studied. The TSPs and ambulance services appeared to be an important factor in rapidly getting the patients to the next available level of care in the battle of Mosul.

The majority of the admitted patients in this study were not injured in the ongoing fighting but needed treatment for everyday surgical illness and conditions such as appendicitis, hernias, abscesses, and injuries after accidents. This is an expected and known outcome, but one that is often ignored while planning the trauma response in conflict settings. Surgeons in a war zone must be trained and experienced in every aspect of acute surgery, not only war

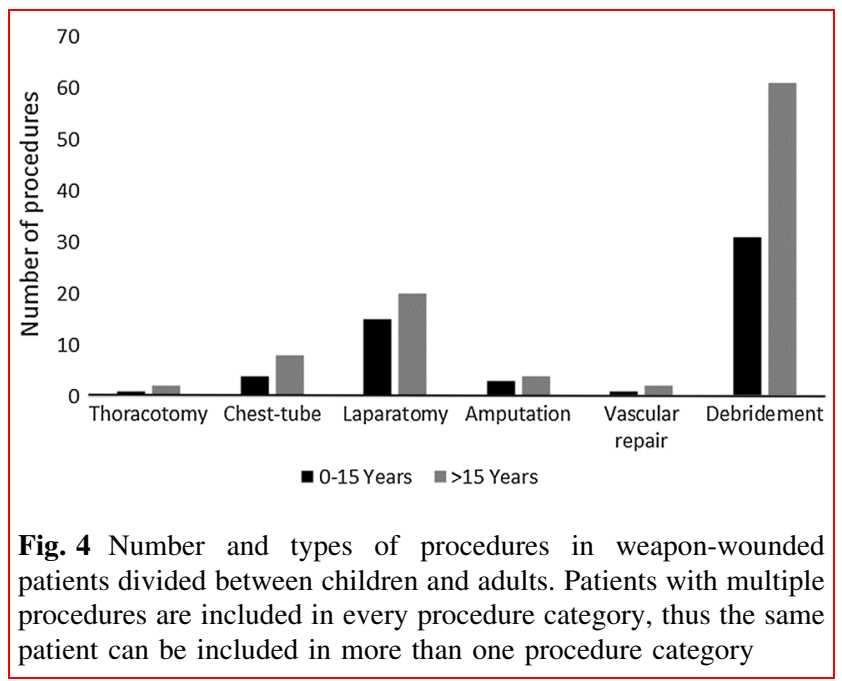

surgery, in adults as well as children. MSF reports similar experiences [18-21]. At the end of the study period, many elective surgery procedures were performed. This could be a result of the workload with weapon-wounded patients declining, giving the medical staff time and resources to do more elective surgery and to work on the backlog of cases built up during the months of the conflict when resources had to be diverted to patients injured by the ongoing conflict and acute surgical illnesses.

\section{Study limitations}

This is a small cohort and only patients admitted to the ICRC services of the hospital were included. The data collection had at the time of collection no clear study objective which probably affected the quality of registration. It is also unclear how this cohort corresponds to that of other field hospitals in the area and their workload under the study period; most of the data from this conflict are not from field hospitals but from hospitals in the city of Erbil, about $60 \mathrm{~km}$ away from Mosul [12]. Patients with obstetric conditions and severe orthopedic limb injuries were all referred to other medical facilities and not included in this study, but are described as being a major part of the patient workload during the study period [7, 18]. One minor finding and possible source of error was that penetrating injuries (by shrapnel and/or bullets) were, in most cases, all classified as caused by "shell" a catch-all term in Arabic that probably have been used in cases where the type of wounding mechanism could not be determined properly [15].

\section{Conclusion}

While Mosul was officially liberated at the beginning of July 2017, a substantial number of patients with weaponrelated injuries were presenting at the ICRC-supported Mosul General Hospital more than 2 months after the fighting officially ceased. However, the majority of patients needing surgical care had everyday illnesses or nonweapon-related injuries. The number of children affected by the fighting seems to be higher in this cohort compared to previous reports. This finding underlines the importance of providing victims of conflicts with surgery for lifethreatening conditions, whether weapon related or not, considering the high number of civilians and children among victims of war.

Acknowledgements Open access funding provided by Linköping University. We would like to thank Lars, Elisabeth, and Jens for help with gathering the data. 
Author contributions FB, DB, PA, and AW designed the study. DB collected the data. LS translated the data. FB and DB validated and analyzed the data. FB prepared the manuscript. FB, DB, LS, PA, and AW critically reviewed the manuscript for style and content.

\section{Compliance with ethical standards}

Conflict of interest The authors have no conflicts of interest to declare. AW was the Chief Surgeon of the ICRC when the data were collected. PA has had several short-term contracts with the ICRC.

Open Access This article is distributed under the terms of the Creative Commons Attribution 4.0 International License (http://crea tivecommons.org/licenses/by/4.0/), which permits unrestricted use, distribution, and reproduction in any medium, provided you give appropriate credit to the original author(s) and the source, provide a link to the Creative Commons license, and indicate if changes were made.

\section{References}

1. Michael M, Meddings DR, Ramez S, Gutierrez-Fisac JL (1999) Incidence of weapon injuries not related to interfactional combat in Afghanistan in 1996: prospective cohort study. BMJ 319(7207):415-417

2. Guha-Sapir D, Schluter B, Rodriguez-Llanes JM, Lillywhite L, Hicks MH (2018) Patterns of civilian and child deaths due to warrelated violence in Syria: a comparative analysis from the violation documentation center dataset, 2011-16. Lancet Glob Health 6(1):e103-e110

3. Hicks MH, Dardagan H, Bagnall PM, Spagat M, Sloboda JA (2011) Casualties in civilians and coalition soldiers from suicide bombings in Iraq, 2003-10: a descriptive study. Lancet 378(9794):906-914

4. Guha-Sapir D, Rodriguez-Llanes JM, Hicks MH et al (2015) Civilian deaths from weapons used in the Syrian conflict. BMJ 351:h4736

5. UN. After Mosul victory, senior UN officials detail Iraq's political and humanitarian needs, July 17, 2017. http://www.un.org/ apps/news/story.asp?NewsID=57192\#.WfY807pFw2w. Accessed 30 March 2018

6. Lafta R, Al-Nuaimi MA, Burnham G (2018) Injury and death during the ISIS occupation of Mosul and its liberation: results from a 40-cluster household survey. PLoS Med 15(5):e1002567

7. Spiegel P, Garber K, Kushner A, Wise P. The Mosul Trauma Response. John Hopkins Center for Humanitarian Health. February 2018. http://www.hopkinshumanitarianhealth.org/ assets/documents/Mosul_Report_FINAL_Feb_14_2018.pdf.

Accessed 30 March 2018
8. Andersson P, Muhrbeck M, Veen H, Osman Z, von Schreeb J (2018) Hospital workload for weapon-wounded females treated by the international committee of the red cross: more work needed than for males. World J Surg 42(1):93-98. https://doi.org/ 10.1007/s00268-017-4160-y

9. Er E, Corbacioglu SK, Guler S et al (2017) Analyses of demographical and injury characteristics of adult and pediatric patients injured in Syrian civil war. Am J Emerg Med 35(1):82-86

10. Coppola CP, Leininger BE, Rasmussen TE, Smith DL (2006) Children treated at an expeditionary military hospital in Iraq. Arch Pediatr Adolesc Med 160(9):972-976

11. Borgman M, Matos RI, Blackbourne LH, Spinella PC (2012) Ten years of military pediatric care in Afghanistan and Iraq. J Trauma Acute Care Surg 73(6 Suppl 5):S509-S513

12. Nerlander MP, Haweizy RM, Wahab MA, Alga A, von Schreeb J (2018) Epidemiology of trauma patients from the Mosul offensive, 2016-2017: results from a dedicated trauma center in Erbil, Iraqi Kurdistan. World J Surg. https://doi.org/10.1007/s00268018-4817-1

13. Celikel A, Karbeyaz K, Kararslan B, Arslan MM, Zeren C (2015) Childhood casualties during civil war: syrian experience. J Forensic Leg Med 34:1-4

14. Terzic J, Mestrovic J, Dogas Z, Furlan D, Biocic M (2001) Children war casualties during the 1991-1995 wars in Croatia and Bosnia and Herzegovina. Croat Med J 42(2):156-160

15. Dardagan H, Salama H (2013) Stolenfutures. ThehiddentollofchildcasualtiesinSyria. Nov 2013. www.everycasualty.org/ downloads/reports/Stolen-Futures.pdf

16. Shabila NP, Taha HI, Al-Hadithi TS (2010) Landmine injuries at the emergency management center in Erbil, Iraq. Confl Health $4: 15$

17. Edwards MJ, Lustik M, Eichelberger MR, Elster E, Azarow K, Coppola C (2012) Blast injury in children: an analysis from Afghanistan and Iraq, 2002-2010. J Trauma Acute Care Surg 73(5):1278-1283

18. Fox H, Stoddard A, Harmer A, Davidoff J (2018) Emergency trauma response to the Mosul offensive, 2016-2917: a review of issues and challenges. Humanitarian Outcomes

19. Trelles M, Dominguez L, Tayler-Smith K et al (2015) Providing surgery in a war-torn context: the Medecins Sans Frontieres experience in Syria. Confl Health 9:36

20. Chu K, Stokes C, Trelles M, Ford N (2011) Improving effective surgical delivery in humanitarian disasters: lessons from Haiti. PLoS Med 8(4):e1001025

21. Chu K, Trelles M, Ford N (2010) Rethinking surgical care in conflict. Lancet 375(9711):262-263

Publisher's Note Springer Nature remains neutral with regard to jurisdictional claims in published maps and institutional affiliations. 